\title{
İrrite Bağırsak Sendromunda Dientamoeba fragilis ve Blastocystis spp.’nin Rolü
}

\author{
Role of Dientamoeba fragilis and Blastocystis spp. in Irritable Bowel Syndrome
}

\section{Ipek Mumcuoğlu¹, Feride Alaca Coşkun¹, Neriman Aksu1, Tuğrul Pürnak², Çiğdem Güngör ${ }^{3}$}

\author{
${ }^{1}$ Ankara Numune Eğitim ve Araştırma Hastanesi, Tıbbi Mikrobiyoloji Kliniği, Ankara, Türkiye \\ ${ }^{2}$ Ankara Numune Eğitim ve Araştırma Hastanesi, Gastroenteroloji Kliniği, Ankara, Türkiye \\ ${ }^{3}$ Ankara Üniversitesi Tıp Fakültesi, Tıbbi Mikrobiyoloji Anabilim Dalı, Tıbbi Parazitoloji Bilim Dalı, Ankara, Türkiye
}

\section{ÖZET}

Amaç: Bu çalışmada, irrite bağırsak sendromu (IBS) tanısı konulmuş hastalarda Dientamoeba fragilis ve Blastocystis spp. parazitlerinin sıklığı ve IBSS oluşumuyla ilişkilerinin araştırılması amaçlanmıştır.

Yöntemler: IBS tanısı almış 55 hastadan, akut gastroenterit şikayetleri olan 80 hastadan oluşan grubu 1'den (KG-1) ve sağlıklı 50 gönüllüden oluşan Kontrol Grubu 2' den (KG-2) toplanan dışkı örnekleri çalışmaya alınmıştır. Örnekler direkt mikroskobi, trikrom boyama ve spesifik kültür yapılarak incelenmiştir.

Bulgular: Blastocystis spp. görülme sıklığı açısından IBS hasta grubu ile KG-1 arasında anlamlı fark görülmezken ( $p>0,05)$, KG-2 arasında anlamlı fark bulunmuştur $(p<0,05)$. IBS hasta grubunda, direkt mikroskobide (X40) her sahada 5 ve üzeri Blastocystis spp. görülmesi kontrol gruplarından daha sıktır. Tedavi sonrası takiplerde $4(\% 22,2)$ hasta şikayetlerinin tamamen geçtiğini bildirirken, 11 (\%61,1) hasta diğer bulgularda hafifleme olmakla birlikte kabızlığın devam ettiğini, $3(\% 16,7)$ hasta ise şikayetlerinde hiçbir değişiklik olmadığını bildirmiştir. Hiçbir örnekte D. fragilis tespit edilmemiştir.

Sonuç: Hiçbir hastada D. fragilis tespit edilememiş olmasının nedeni bölgemizde bu parazitin infeksiyon oranının düşük olmasına bağlı olabilir. IBS hastalarında her mikroskobi sahasında (X40) 5 ve üzeri Blastocystis spp.'nin sık görülmesi ve bu hastaların önemli bir kısmında tedavi ile şikayetlerin gerilemesi, iBS ile Blastocystis spp. enfeksiyonları arasında bir bağlantı olabileceğini düşündürmüştür. (Turkiye Parazitol Derg 2013; 37: 73-7)

Anahtar Sözcükler: Blastocystis spp., Dientamoeba fragilis, irrite bağırsak sendromu, Robinson besiyeri, trikrom boyama Geliş Tarihi: 08.12.2011 Kabul Tarihi: 16.01.2013

\begin{abstract}
Objective: We investigated the prevalence of Dientamoeba fragilis and Blastocystis spp. in IBS patients and evaluated whether there was a possible link between IBS and these parasitic infections.

Methods: Stool specimens collected from 55 IBS patients, 80 patients with gastroenteritis as control group 1 (CG-1) and 50 healthy volunteers as control group 2 (CG-2) were included the study. Samples were examined by direct microscopy, trichrome staining and culture methods. Results: While there was no significant difference in the prevalence of Blastocystis spp. between IBS patients and CG-1 ( $p>0.05)$, a significant difference was found between IBS and CG-2 $(p<0.05)$. Patients with IBS were found to have five or more Blastocystis spp. per field than control groups. After eradication, all symptoms were cured in four patients, there were only constipation problems left in eleven patients and there were no changes in clinical findings in three patients. D. fragilis was not found in any of the samples.

Conclusion: The reason we did not find any D. fragilis may be due to the low infection rate in the region. However, significantly having five or more Blastocystis spp. per field (X40) in IBS patients and regression of IBS symptoms after treatment in most of the patients suggested a possible link between IBS and Blastocystis spp. (Turkiye Parazitol Derg 2013; 37: 73-7)
\end{abstract}

Key Words: Blastocystis spp., Dientamoeba fragilis, irritable bowel syndrome, Robinson culture medium, trichrome stain

Received: 08.12.2011 Accepted: 16.01.2013

22. Avrupa Klinik Mikrobiyoloji ve Enfeksiyon Hastalıkları Kongresi. 31 Mart-3 Nisan 2012. Londra, Birleşik Krallık. Poster No: 2084 22. European Congress of Clinical Microbiology and Infectious Disease 31 March-3 April 2012 London, UK. Poster No: 2084.

Yazışma Adresi / Address for Correspondence: Dr. İpek Mumcuoğlu, Ankara Numune Eğitim ve Araştırma Hastanesi, Tıbbi Mikrobiyoloji Kliniği, Ankara, Türkiye Tel: +90 3125084477 E-posta: ipekmumcuoglu@hotmail.com

doi:10.5152/tpd.2013.19 


\section{Giriş}

Bu çalışmada, Roma III tanı kriterlerine (1) göre irrite bağırsak sendromu (IBS) tanısı konulmuş hastaların dışkılarında Dientamoeba fragilis ve Blastocystis spp. parazitlerinin prevalansının mikroskobi ve kültür yöntemleri ile araştırılması, ve bu parazitlerin IBS oluşumuyla bağlantılarııı olup olmadığının değerlendirilmesi amaçlanmıştır.

İrrite bağırsak sendromu, başlıca semptomları karın ağrısı ya da huzursuzluk olan, bağırsak alışkanlıklarında değişikliklerle seyreden, etiyolojisi tam olarak bilinmeyen, kronik ve tekrarlayıcı bir hastalıktır (2).

Dünya genelinde IBS görülme sıklığı \%4-35 arasında bildirilmektedir (2). Türkiye'de Roma-II kriterlerine göre yapılan populasyon çalışmalarında, iBS prevelansı \%19 olarak bulunmuştur (3). Yapılan epidemiyolojik çalışmalarda kadınların çoğunlukta olduğu (kadın erkek oranı 2/1) ve büyük çoğunluğu 45 yaş altı nüfusun oluşturduğu saptanmıştır (4).

iBS'de patofizyoloji tam anlaşılmış değildir. Etiyolojik faktör bilinmediğinden hastalığın oluşum mekanizması da açıklığa kavuşmamıştır. Son yıllarda bilimsel gelişmeler ışığında IBS oluşumunda rolü olduğu düşünülen faktörlerden birisi bağırsak enfeksiyonu ve inflamasyonudur (3).

D. fragilis bilimsel literatürde ilk defa 1907 yılında Wenyon tarafindan bulunmuş, daha sonra 1918 yılında Jepps ve Dobell tarafından tanımlanmış amibe benzeyen, sadece trofozoit formu bulunan, insan çekum ve kalın barsağının lümeninde yaşayan bir protozoondur (5). Keşfedileli 90 yıl gibi bir süre olmasına rağmen, bu protozoonla ilgili bilgiler diğer protozoonlarla karşılaştırıldığında çok azdır. Yaşam döngüsü ve bulaş yolları bilinmemektedir ve üretilmesi için geliş̧irilmiş aksenik kültür veya hayvan modelleri yoktur. Bununla beraber son zamanlarda yapılan çalışmalar bu organizmanın anlaşıımasına belirgin bir katkıda bulunmuş ve bu patojenin belirsizlikten çıkmasını sağlamışıı. Illk kez Borody ve ark. (6), D. fragilis ile IBS arasında bağlantı olduğunu ileri sürmüşlerdir. Avustralya'da yapılan bu çalışmada, iBS şikayeti olan 21 hastada D. fragilis enfeksiyonu varlığı gösterilmiş ve iyodokuinoldoksisiklin tedavisinden sonra $D$. fragilis eradikasyonu ve hastaların çoğunda klinik iyileşme görüldüğü bildirilmiştir.

Dünyada prevalans \%1.4 ile \%52 arasında değişmektedir (5). Ülkemizde yapılan az sayıda çalışmada ise $D$. fragilis prevalansı İzmir, Van, Malatya ve Manisa bölgesinde sırasıly \%0,2; \%0,4; $\% 0,4$ ve \%1,02 olarak bildirilmiştir (7-10).

Blastocystis pek çok hayvan ve insanın enterik protozoon parazitidir. Tüm dünyada yaygın olarak bulunmaktadır. Parazit $1900^{\prime} \mid u ̈$ yılların başından itibaren bilinmesine rağmen sadece son on yıldır Blastocystis biyolojisini açıklayan gelişmeler olmuştur. Bununla birlikte parazitin pleomorfik yapısı ve standardize tetkiklerin bulunmaması verilerde yanlış yorumlamalara neden olmaktadır. Bu durum parazitin laboratuvar tanısında ve çoğalması, yaşam siklusu, prevalans ve patogenezinin anlaşılmasında aksamalara neden olmaktadır. Artan epidemiyolojik, in vivo ve in vitro çalışmalar Blastocystis'in patojen olduğunu düşündürmektedir. Doğada birçok genotip mevcuttur ve insan çok sayıda zoonotik genotipin konağıdır. Bu genetik çeşitliliğin, patogenezle ilgili akıl karıştııııı bilgilerden sorumlu olabileceği düşünülmektedir (11).
İki çalışmada IBS hastalarında Blastocystis'e daha sık rastlanıldığı bildirilmektedir $(12,13)$. Serolojik bir çalışmada ise IBSS hastalarında Blastocystis'e karşı IgG2 değerlerinin yüksek olduğu bulunmuştur (14). Bazı araştıııcılar ise kontrol grubu ile karşılaştııı dığında IBS ile Blastocystis spp. enfeksiyonları arasında herhangi bir korelasyon olmadığını bildirmişlerdir (15). Udkow ve Markell (16), IBS'de oluşan anormal intestinal koşulların parazitin aşırı çoğalması için uygun ortam sağlayabileceğinin öne sürmektedir. Mevcut veriler IBS ile Blastocystis spp. arasında bir ilişki olduğunu düşündürmekle birlikte Blastocystis spp. henüz IBS'nin etyolojik ajanı olarak kabul edilmemektedir.

\section{YÖNTEMLER}

Eylül 2009-Şubat 2010 tarihleri arasında Roma III kriterlerine göre iBS tanısı konulan 55 hasta, çeşitli polikliniklere gastroenterit şikayetleriyle başvuran 80 hasta ve hastaneye başka şikayetlerle başvurmuş hiçbir gastroenterit şikayeti olmayan 50 sağlıklı gönüllüye ait dışkı örnekleri laboratuvarımızda incelemeye alınmıştır.

Hastanemiz Gastroenteroloji Kliniği'ne başvurarak Roma III kriterlerine göre IBSS tanısı almış 55 hasta çalışmaya dahil edilmiştir (1). Bu hastalara fizik muayenenin yanı sıra tam kan sayımı, sedimentasyon, karaciğer fonksiyon testleri, üre, kreatinin, dışkıda gizli kan testi yapılmıştır. Roma III kriterlerinin tamamına uyan bu hastaların hepsine kolonoskopi uygulanmıştır. Hastalar laboratuvara dışkı incelemesi için yönlendirilmiş ve her bir hasta için hasta takip formuna, klinik semptomları, yaş, cinsiyet, varsa diğer hastalıkları, yolculuk hikayeleri, immün durumları, geçirdikleri paraziter enfeksiyonlar ve iletişim bilgileri not edilmiştir.

Hastanemiz çeşitli polikliniklerine gastroenterit şikayetleriyle başvuran 80 hasta Kontrol Grubu 1 (KG-1) olarak ve hastaneye başka şikayetlerle başvurmuş hiçbir gastroenterit şikayeti olmayan 50 sağlıklı gönüllü Kontrol Grubu 2 (KG-2) olarak hasta takip ve rapor formuna bilgileri kaydedilerek çalışmaya dahil edilmiştir.

Laboratuvara teslim edilen tüm dışkı örneklerinden bekletilmeden trikrom ve Modifiye Ehrlich-Ziehl-Neelsen boyama için preparatlar hazırlanmıș, nativ-Lugol incelemeleri yapılmıș, D. fragilis için Robinson besiyerine ve Blastocystis spp. için at serumluasparjinli Ringer solüsyonuna ekimler yapılmıştır $(17,18)$. Dışkı örnekleri ayrıca bakteriyolojik olarak Salmonella, Shigella, Campylobacter ve E. coli O157 enfeksiyonu açısından standart prosedürlerle incelenmiştir. Dışkıların C. difficile toksin ve viral etkenler açısından incelemeleri yapılmamıştır.

D. fragilis tespit edilen hastalara Girginkardeşler ve ark. (19), önerisi doğrultusunda, yetişkinlere $2 \mathrm{~g}$ tek doz olarak seknidazol verilmesi planlanmıştır. Blastocystis spp. tespit edilen hastalarda

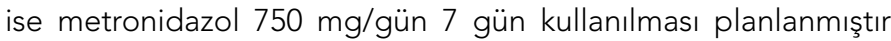
$(20,21)$. Sağaltım tamamlandıktan bir hafta sonra tüm hastalar kontrole çağrılmış, kısa bir görüşme yapılıp semptomların ortadan kalkıp kalkmadığı, verilen ilacın yan etkiye yol açıp açmadığı sorgulanmış, daha sonra aynı yöntemlerle dışkının parazitolojik incelemesi yapılmış ve parazitin eradike olup olmadığı araştııımıştır. Eradikasyonun sağlanmaması durumunda $D$. fragilis için hastaya aynı dozda ikinci bir seknidazol kürü verilmesi, Blastocystis spp. için ise trimetoprim-sulfametaksazol (320 mg TMP, $1600 \mathrm{mg}$ SMX) 7 gün verilmesi planlanmışır (22). Sağaltım tamamlandıktan bir hafta sonra kontroller tekrarlanmıştır. 


\section{İstatistiksel Analiz}

Analizlerde SPSS (Statistical Package for Social Sciences) 11,5 PC programı kullanıldı. Kategorik değişkenlerin analizinde Ki-kare testi (ve/veya Fisher' s exact testi) kullanıldı. $\mathrm{p}<0,05$ değeri istatistiksel olarak anlamlı kabul edildi.

\section{BULGULAR}

Hastanemiz Gastroenteroloji Polikliniği'ne başvurarak Roma III kriterlerine göre IBS tanısı almış 13 erkek 42 kadın olmak üzere 55 hasta çalışmaya dahil edilmiştir. Hastaların yaş ortalaması $37,07 \pm 11,17$ olarak bulunmuştur. Hastalarda, karın ağrısı $(\% 83,6)$, kabızlık (\%80) ve şişkinlik $(\% 78,2)$ en sık rastlanan şikayetlerdi. İshal $(\% 30,9)$, bulantı $(\% 23,6)$, kusma (\%9) ve iştahsızlık (\%7) görülen diğer şikayetlerdi. Semptomlar kadın ve erkeklerde eşit dağılımdaydı. Çalışmaya alınan hastaların şikayetleri en az 6 ay, en çok 10 yıldır devam etmekteydi (ort 2,6 yıl). On hasta son bir yıl içinde yurt içi yakın illere seyahat ettiğini bildirirken, hiçbir hasta yurt dışına çıkmamıştır. Yedi kişide daha önce geçirilmiş kıl kurdu, 3 kişide şerit düşürme ve 1 kişide Giardia enfeksiyonu hikayesi mevcuttu. Hastaların 16'sında $(\% 29,1)$ direkt mikroskobi ile, 18 'inde $(\% 32,7)$ trikrom boyama ve kültür yöntemi ile Blastocystis spp. tespit edilmiştir. Blastocystis spp.,10 kadın ve 8 erkek hastada saptanmıştır. Direkt mikroskobilerinde Blastocystis spp. tespit edilen 16 hastanın tamamında her sahada 5 ve üzeri Blastocystis spp. görülmüştür. Yurt içi seyahat, cinsiyet, yaş gibi faktörler ile Blastocystis enfeksiyonu arasında korelasyon görülmemiştir $(p=0,2)$. Blastocystis spp. tanısında kültür yöntemi altın standart olmakla birlikte, IBS Hasta Grubu'nda; direkt mikroskobi, trikrom boyama ve kültür yöntemleri tanısal olarak karşılaştırıldığında istatistiksel olarak anlamlı fark bulunmamıştır ( $p>0,05)$. Her üç yöntemle hiçbir hastada D. fragilis tespit edilmemiştir. Yapılan bakteriyolojik kültürlerde Salmonella spp., Shigella spp., Campylobacter spp. ve E.coli 0157 izole edilmemiştir. Yapılan nativ-Lugol, trikrom ve Modifiye Ehrlich-Ziehl-Neelsen boyama incelemeleri sonucunda Blastocystis spp. harici patojen ya da apatojen hiçbir parazite rastlanmamıştır. Hastaların 18'inde $(\% 32,7)$ direkt mikroskobik incelemede dikkati çekecek şekilde floraya hakim olmuş mantar sporlarının varlığı not edilmiştir.

Hastanemiz çeşitli polikliniklerine akut gastroenterit şikayetleriyle başvuran 80 hasta KG-1 olarak isimlendirilmiştir. Bu grupta 33 erkek ve 47 kadın hasta mevcuttu ve yaşları 4 ila 81 arasında değişmekte idi (ortalama 32,0). Hastalarda, karın ağrısı $(\% 88,8)$, ishal $(\% 73,8)$ ve kusma $(\% 22,5)$ en sık rastlanan şikayetlerdi. Çalışmaya alınan hastaların şikayetleri en az 1 gün en çok 5 gündür devam etmekteydi. Bu hasta grubunda; 1 kişide Salmonella spp., 2 kişide Giardia intestinalis, 1 kişide lodamoeba butschlii ve 1 kişide de Entamoeba coli tespit edilmiştir. Hastaların 6'sında $(\% 7.5)$ direkt mikroskobi ile, 8 'inde $(\% 10,0)$ trikrom boyama ile ve 15'inde (\%18.8) kültür yöntemi ile Blastocystis spp. tespit edilmiştir. Direkt mikroskobilerinde Blastocystis spp. tespit edilen 6 hastanın tamamında her sahada 5 ve üzeri Blastocystis spp. görülmüştür. lodamoeba butschlii ve Entamoeba coli görülen kişilerin her ikisinde Blastocystis spp.'de tespit edilmiştir. KG-1'de; Blastocystis spp. tanısında direkt mikroskobi, trikrom boyama ve kültür yöntemleri tanısal olarak karşılaştırıldığında istatistiksel olarak direkt mikroskobi ile kültür arasında anlamlı fark bulunurken $(p<0,05)$, Trikrom boyama ile kültür arasında anlamlı fark bulunmamıştır $(p>0,05)$. Her üç yöntemle hiçbir hastada $D$. fragilis tespit edilmemiştir.
Hastanemize başka şikayetlerle başvurmuş hiçbir gastroenterit şikayeti olmayan 50 sağlıklı gönüllü KG-2 olarak isimlendirilmiştir. Bu grupta 17 erkek ve 33 kadın hasta mevcuttu ve yaşları 15 ila 59 arasında değişmekteydi (ortalama 34,5). Bu hasta grubunda; 1 kişide $(\% 2,0)$ direkt mikroskobi ve trikrom boyama ile ve 3 kişide (\%6) kültür yöntemi ile Blastocystis spp. tespit edilmiştir. Direkt mikroskobi ile Blastocystis spp. tespit edilen hastanın incelemesinde her sahada 5 'ten az Blastocystis spp. görülmüştür. KG-2' de başka bir bakteriyel veya paraziter patojene rastlanmamıştır. İrrite bağırsak sendromlu hasta grubu, KG-1 ve KG-2'de direkt mikroskobi, trikrom boyama ve kültür yöntemi ile tespit edilen Blastocystis spp. ile infekte hastalar Tablo 1'de özetlenmiştir. Blastocystis spp. tespit edilen hasta sayıları karşılaştırıldığında, IBS hasta grubu ile KG-1 arasında istatistiksel olarak anlamlı fark bulunmamıştır ( $p>0,05)$.

Irrite Bağırsak Sendromlu hasta grubundan ve KG-2'den Blastocystis spp. tespit edilen hasta sayıları karşılaştırıldığında istatistiksel olarak anlamlı fark bulunmuştur $(p<0,05)$.

Blastocystis spp. tespit edilen hastalar telefonla haberdar edilerek hastanemiz Gastroenteroloji Kliniği'ne veya en yakın Sağlık Ocağı'na tedavi olmak üzere yönlendirilmişlerdir. Tedavi için metronidazol 750 mg/gün 7 gün kullanılmıştır. Sağaltım tamamlandıktan bir gün sonra tüm hastalar kontrole çağrılmış, kısa bir görüşme yapılıp semptomlarının ortadan kalkıp kalkmadığı sorgulanmış, daha sonra aynı yöntemlerle dışkının parazitolojik incelemesi yapılmış ve parazitin eradike olup olmadığı araştırılmıştır. IBS hasta grubunda Blastocystis spp. tespit edilen 18 hastanın 12'sinde (\%67) tedavi sonrası parazitin eradike olduğu görülmüş, geri kalan 6 hastaya trimetoprim-sulfametaksazol (320 mg TMP, 1600 mg SMX) 7 gün verilmiştir. Bu 6 (\%33) hastanın da tedavi sonrası parazitolojik incelemelerinde parazitin tamamen eradike olduğu görülmüştür. Tedavi sonrası 15. gün ve 1. ayda yapılan görüşmelerde 4 kişi $(\% 22,2)$ (3 erkek, 1 kadın) şikayetlerinin tamamen geçtiğini bildirirken, $11(\% 61,1)$ hasta diğer bulgularda hafifleme olmakla birlikte kabızlığının devam ettiğini bildirmiş, $3(\% 16,7)$ hasta ise şikayetlerinde hiçbir değişiklik olmadığını bildirmiştir.

KG-1'de, direkt mikroskobi ile her sahada 5 veya daha fazla Blastocystis spp. görülen 6 hastaya metronidazol tedavisi önerilmiştir. Bu hastalardan hiçbiri kontrole gelmemiştir. Telefonla ulaşılabilen 5 hasta şikayetlerinin tamamen geçtiğini bildirmiştir.

KG-2'de Blastocystis spp. tespit edilen hastalara tedavi önerilmemiştir.

Tablo 1. İrite bağırsak sendromlu hasta grubu, kontrol grubu 1 ve 2 'de direkt mikroskobi, trikrom boyama ve kültür yöntemi ile tespit edilen Blastocystis spp. infekte kişi sayıları

\begin{tabular}{|l|c|c|c|}
\hline & $\begin{array}{c}\text { iBS Hasta } \\
\text { Grubu } \\
\mathbf{n}(\%)\end{array}$ & $\begin{array}{c}\text { Kontrol } \\
\text { Grubu } \\
\mathbf{1} \mathbf{n}(\%)\end{array}$ & $\begin{array}{c}\text { Kontrol } \\
\text { Grubu } \\
\mathbf{2} \mathbf{n}(\%)\end{array}$ \\
\hline Direkt Mikroskobi & $16(\% 29,1)$ & $6(\% 7,5)$ & $1(\% 2,0)$ \\
\hline Trikrom Boyama & $18(\% 32,7)$ & $8(\% 10,0)$ & $1(\% 2,0)$ \\
\hline Kültür & $18(\% 32,7)$ & $15(\% 18,8)$ & $3(\% 6)$ \\
\hline Toplam & $18(\% 32,7)$ & $15(\% 18,8)$ & $3(\% 6)$ \\
\hline
\end{tabular}




\section{TARTIŞMA}

IBS ülkemizde \%12,4 ile \%19 oranında görülen dünyada ise \%4-35 arasında görülen, kişinin günlük yaşam kalitesini bozan, karın ağrısı, diyare ve/veya kabızlıkla karakterize kronik bir hastalıktır $(2,3,7,23)$. Nedeni tam bilinmemekte ve temelde psikonörotik bir hastalık olduğu düşünülmekle birlikte son çalışmalarda IBS hastalarında bağırsakta kronik bir immün aktivasyon olduğu tespit edilmiştir (24). Araştırmalar, IBS vakalarının önemli bir kısmında mikroskobi ve kültür yöntemleri ile Blastocystis spp. ve $D$. fragilis protozoonlarının varlığından söz etmektedir $(25,26)$.

Blastocystis spp., insanlarda en sık rastlanan intestinal protozoonlardan birisidir. Gittikçe daha fazla sayıda yayında parazitin gastrointestinal sistem (GiS) şikayetlerinden sorumlu olduğu bildirilmesine rağmen, bu organizmanın spesifik patojenitesi tam olarak belirlenememiştir. Yapılan çalışmalarda IBS hastalarında Blastocystis spp.'ye daha sık rastlandığı bildirilmiştir $(12,13)$. Patogenezle ilgili akıl karıştırıcı bilgilerin patojenik ve nonpatojenik genotiplerin varlığından kaynaklandığı düşünülmektedir (27).

D. fragilis, sadece trofozoit formu bulunan, insan çekum ve kalın barsağının lümeninde yaşayan bir protozoondur. D. fragilis'in hiç klinik semptom göstermeyen hastalarda da bulunmuş olması ve sıklıkla diğer patojenlerle birlikte görülmesi, patojenitesiyle ilgili tartışmalara neden olmuştur (5). Bir çok çalışma bu parazitin eliminasyonunun klinik iyileşme sağladığını gösterirken $(5,28)$. bazı çalışmalar da $D$. fragilis'in prevalansının $G$. intestinalis'ten fazla olduğunu göstermektedir $(19,29)$. Borody ve ark. (6), IBSS benzeri semptomlara yol açan kronik hastalık yaptığı için bazı hastalarda $D$. fragilis enfeksiyonunun IBS olarak yanlış tanı almakta olduğu bildirilmiştir.

Çalışmamızda IBS tanısı alan 55 hastaya, çeşitli polikliniklere gastroenterit şikayetleriyle başvuran 80 hastaya ve hiçbir gastroenterit şikayeti olmayan 50 sağlıklı gönüllüye ait dışkı örnekleri, Blastocystis spp. ve D. fragilis açısından incelemeye alınmıştır.

Roma III kriterlerine göre yapılan çalışmalarda kadın/erkek oranı genellikle 2:1 olarak bildirilirken (4) bizim çalışmamızda 3:1 olarak tespit edilmiştir.

Blastocystis spp. görülme sıklığı açısından İBS hasta grubu ile gastroenteritli hastalardan oluşan KG-1 arasında anlamlı fark görülmemiştir $(p>0,05)$. IBS hasta grubu ve KG-1 ile GiS şikayetleri olmayan KG-2 arasında anlamlı fark bulunmuştur $(p<0,05)$. Blastocystis spp.'nin patojenitesi hala tartışmalıdır. Bunun nedeninin konak faktörleri, genotip farklılıkları ve alınan parazit sayısı ile ilişkili olabileceği belirtilmiştir. IBS grubunda konak faktörü ve genotipe bağlı olarak daha patojen türler yer alırken, KG-1'de patojen ve apatojen genotiplerin bulunması olasıdır.

IBS hasta grubunda direkt mikroskobi ve boyama ile tanı, kültür yöntemi ile aynı güvenilirlikte bulunurken ( $p>0,05)$, kontrol gruplarında direkt mikroskobi ve boyama yönteminin kültür kadar tanı sağlamaması $(p<0,05)$ IBS hastalarında parazit sayısının daha yüksek olduğunu düşündürmüştür. Direkt mikroskobilerinde Blastocystis spp. tespit edilen 16 hastanın tamamında her sahada 5 ve üzeri Blastocystis spp. görülmesi bu düşünceyi doğrulamaktadır.

KG-1'de direkt mikroskobide her sahada 5 ve üzeri Blastocystis spp. tespit edilen 6 hastanın tamamında başka hiçbir patojene rastlanmamış olması ve tedavi sonrası şikayetlerin geçmesi
Blastocystis spp.'nin şikayet ve mikroskobi eşliğinde değerlendirilerek tedavi edilmesi gereken bir patojen olduğuna dair inancı güçlendirmektedir.

IBS hasta grubunda yurt içi seyahat, cinsiyet, yaş gibi faktörler ile Blastocystis enfeksiyonu arasında korelasyon görülmemiştir $(p=0,2)$.

Giacometti ve ark. (12), 81 iBS'li hastanın 15'inde (\%18,5) Blastocystis spp. göstermiş bu oranın diğer GiS şikayetleri olan hastalardaki orandan yüksek olduğunu (\%0.7) bildirmişlerdir. Ayrıca bizim çalışmamızla benzer olarak IBS hastalarında her mikroskobi sahasında daha fazla parazit görüldüğünü bildirmişlerdir.

Yakoob ve ark. (13), IBS hastalarının \%32'sinde direkt mikroskobi ve \%46'sında kültür ile Blastocystis spp. pozitifliği bulmuş ve bu oranın kontrol grubundakinden (\%7) anlamlı şekilde yüksek olduğunu bildirmişlerdir. Bizim çalışmamızdan farklı olarak bu çalışmada, kültür yöntemi direkt mikroskobiye üstün görülmektedir.

Bu çalışmalardan farklı olarak Tungtrongchitr ve ark. IBS hastalarının \%13.6'sında Blastocystis spp. pozitifliği bulmuş ve bu oranın kontrol grubundan farklı olmadığını bildirmiştir (15). Ancak bu çalışmada sadece direkt mikroskobi ve Trikrom boyama kullanılmış, kültür yöntemi kullanılmamıştır.

IBS Hasta Grubu'nda Blastocystis spp. tespit edilen 12 (\%67) hastada metronidazol ile 6 (\%33) hastada trimetoprim-sulfametaksazol ile parazit eradikasyonu sağlanmıştır. Tedavi sonrası 15. gün ve 1. ayda yapılan görüşmelerde $4(\% 22,2)$ hasta (3 erkek, 1 kadın) şikayetlerinin tamamen geçtiğini bildirirken, $11(\% 61,1)$ hasta diğer bulgularda hafifleme olmakla birlikte kabızlığının devam ettiğini, $3(\% 16,7)$ hasta ise şikayetlerinde hiçbir değişiklik olmadığını bildirmiştir. Yapılan çalışmalarda Blastocystis spp. enfeksiyonlarında kronik bir immün aktivasyon olduğu ve parazitin bağırsak epiteline yapışarak E. histolytica benzeri lizis mekanizması başlattığı ve kültür filtratlarında bir diyarejenik toksin varlığı bildirilmiştir $(24,30)$. Bunlar göz önüne alındığında immün durumuna bağlı olarak iyileşme süresinin kişiye göre değişebileceği ve bu kişilerin şikayetlerindeki iyileşmeyi gözleyebilmek için daha uzun süre takip edilmesi gerektiği düşünülmüştür. Ayrıca Blastocystis spp.'nin patojenitesinde genotiplerin rolünün de hala tartışıldığı düşünülürse, iyileşmedeki farlılıklarının sebebinin bu olabileceği düşünülmektedir. Udkow ve Markell iBS hastalarında oluşan anormal intestinal koşulların bazı non-patojen subgrupların aşırı çoğalması için uygun ortam sağlayabileceğini öne sürmüştür (16).

iBS grubu hastaların 18'inde $(\% 32,7)$ direkt mikroskobik incelemede mantar sporlarının floraya hakim olması dikkati çekmiş ancak bunun kabızlık nedeniyle pasajı yavaşlamış dışkıda mayaların aşırı çoğalması ile ilişkili olabileceği düşünülmüştür.

Her üç yöntemle hiçbir hastada D. fragilis tespit edilmemiştir. Parazitin çabuk parçalanan doğası ve kist evresinin olmaması nedeniyle, bulaşın Enterobius vermicularis yumurtalarıyla gerçekleştiğini öneren çalışmalar vardır $(31,32)$. Bu çalışmada, IBSS hasta grubunda 7 kişi geçirilmiş kıl kurdu enfeksiyonu hikayesi vermiş, ancak bu hastalarda D. fragilis'e rastlanmamıştır.

Ülkemizde D. fragilis epidemiyolojisiyle ilgili yeterince çalışma yoktur. Sadece boyama yöntemi kullanılarak yapılan çalışmalarda D. fragilis prevalansı \%0,2 ile \%1,02 arasında bildirilmiştir (7-10). 


\section{SONUÇ}

Çalışmamızda hem hasta hem de kontrol gruplarında hiç D. fragilis rastlanmamış olmasının nedeni, bölgemizde artan kişisel hijyen bilincine paralel olarak enfeksiyon oranlarının çok düşük olması olabilir. Bölgemizde ve ülkemizde D. fragilis epidemiyolojisi ile ilgili çalışmalara ihtiyaç vardır.

iBS hastalarında her mikroskobi sahasında (X40) 5 ve üzeri Blastocystis spp'nin sık görülmesi ve bu hastaların önemli bir kısmında tedavi ile şikayetlerin gerilemesi, IBS ile Blastocystis spp. enfeksiyonları arasında bir bağlantı olabileceğini düşündürmüştür.

\section{Çıkar Çatışması}

Yazarlar herhangi bir çıkar çatışması bildirmemişlerdir.

Hakem değerlendirmesi: Dış bağımsız.

\section{Yazar Katkıları}

Fikir - I.M.; Tasarım - I.M., Ç.G.; Denetleme - N.A.,Ç.G.; Kaynaklar i.M.; Malzemeler - I.M., T.P.; Veri toplanması ve/veya işlemesi i.M., F.A.C., T.P.; Analiz ve/veya yorum - I.M.,Ç.G.; Literatür taraması - I.M.; Yazıyı yazan - I.M.; Eleştirel Inceleme - N.A., Ç.G.

\section{Conflict of Interest}

No conflict of interest was declared by the authors.

Peer-review: Externally peer-reviewed.

\section{Author Contributions}

Concept - I.M.; Design - I.M., Ç.G.; Supervision - N.A.,Ç.G.; Funding - I.M.; Materials - I.M. T.P; Data Collection and/or Processing - I.M., F.A.C., T.P.; Analysis and/or Interpretation i.M.,Ç.G.; Literature Review - I.M.; Writing - I.M.; Critical Review - N.A., Ç.G.

\section{KAYNAKLAR}

1. Drossman DA. The The functional gastrointestinal disorders and the Rome III process. Gastroenterology 2006; 130:1377-90. [CrossRef]

2. Longstreth GF, Thompson WG, Chey WD, Houghton LA, Mearin F, Spiller RC. Functional bowel disorders. Gastroenterology 2006;130:1480-91. [CrossRef]

3. Özden A, Köksal AS, Oğuz D, Çiçek B, Yılmaz U, Dağlı Ü, ve ark. Türkiye' de birinci basamak sağlık kurumlarında irritabl bağırsak sendromu görülme sıklığı. Akademik Gastroenteroloji Dergisi. 2006; 5: 4-15.

4. Saito YA, Schoenfeld P, Locke GRI 3rd. The epidemiology of irritable bowel syndrome in North America: a systemic rewiew. Am J Gastroenterol 2002; 97: 1910-5. [CrossRef]

5. Johnson EH, Windsor JJ, Clark CG. Emerging from obscurity: biological, clinical, and diagnostic aspects of Dientamoeba fragilis. Clin Microbiol Rev 2004; 17: 553-70. [CrossRef]

6. Borody TJ, Warren EF, Wettstein A, Robertson G, Recabarren $P$, Fontela A, et al. Eradication of Dientamoeba fragilis can resolve IBSlike symptoms. J Gastroenterol Hepatol. 2002; 17(Suppl): A103.

7. Inceboz T, Üner A. Blastocytis hominis in epidemiyolojisinin araştııılması. Türkiye Parazitol Derg 2001; 25: 135-8.

8. Cengiz Z, Akbayram S, Çiçek M. Van'da ilköğretim okulu öğrencilerinde saptanan bağırsak parazitozları. Türkiye Parazitol Derg. 2009; 33: 289-93.

9. Karaman Ü, Atambay M, Aycan Ö, Yoloğlu S, Daldal N. Malatya temizlik işçilerinde bağırsak parazitlerinin görülme oranı. Türkiye Parazitol Derg 2006; 30: 181-3.

10. Yılmaz U, Östan I, Kayran E, Özbilgin A. Celal Bayar Üniversitesi Araştırma ve Uygulama Hastanesi'nde 2000-2001 yıllarında saptanan bağırsak parazitlerinin dağılımı. Türkiye Parazitol Derg 2002; 26: 60-3.
11. Tan KS. New insights on classification, identification, and clinical relevance of Blastocystis spp. Clin Microbiol Rev 2008; 21: 639-65. [CrossRef]

12. Giacometti A, Cirioni O, Fiorentini A, Fortuna M, Scalise G. Irritable bowel syndrome in patients with Blastocystis hominis infection. Eur $\mathrm{J}$ Clin Microbiol Infect Dis 1999; 18: 436-9. [CrossRef]

13. Yakoob J, Jafri W, Jafri N, Khan R, Islam M, Beg MA, et al. Irritable bowel syndrome: in search of an etiology: role of Blastocystis hominis. Am J Trop Med Hyg 2004; 70: 383-5.

14. Hussain R, Jaferi W, Zuberi S, Baqai R, Abrar N, Ahmed A, et al. Significantly increased lgG2 subclass antibody levels to Blastocystis hominis in patients with irritable bowel syndrome. Am J Trop Med Hyg 1997; 56: 301-6.

15. Tungtrongchitr A, Manatsathit $S$, Kositchaiwat $C$, Ongrotchanakun J, Munkong N, Chinabutr P, et al. Blastocystis hominis infection in irritable bowel syndrome patients. Southeast Asian J Trop Med Public Health 2004; 35: 705-10.

16. Udkow MP, Markell EK. Blastocystis hominis: prevalence in asymptomatic versus symptomatic hosts. J Infect Dis 1993; 168: 242-4. [CrossRef]

17. Clark CG, Diamond LS. Methods for cultivation of luminal parasitic protists of clinical importance. Clin Microbiol Rev 2002; 15: 329-41. [CrossRef]

18. Yoshikawa H, Wu Z, Kimata I, Iseki M, Ali IK, Hossain MB, et.al. Polymerase chain reaction-based genotype classification among human Blastocystis hominis populations isolated from different countries. Parasitol Res 2004; 92: 22-9. [CrossRef]

19. Girginkardeşler N, Coşkun S, Balcıoğlu I, Ertan P, Ok UZ. Dientamoeba fragilis, a neglected cause of diarrhea, successfully treated with secnidazole. Clin Microbiol Infect 2003; 9: 110-3. [CrossRef]

20. Nigro L, Larocca L, Massarelli L, Patamia I, Minniti S, Palermo F, et al. A placebo-controlled treatment trial of Blastocystis hominis infection with metronidazole. J Travel Med 2003; 10: 128-30. [CrossRef]

21. Taşova $Y$, Şahin B, Koltaş S, Paydaş S. Clinical significance and frequency of Blastocystis hominis in Turkish patients with hematological malignancy. Acta Med Okayama 2000; 54: 133-6.

22. Ok UZ, Girginkardeşler N, Balcıoğlu C, Ertan P, Pırıldar T, Kilimcioğlu AA. Effect of trimethoprim-sulfamethaxazole in Blastocystis hominis infection. Am J Gastroenterol 1999; 94: 3245-7. [CrossRef]

23. Akpınar H. Ege Bölgesinde Irrite Bağırsak Sendromu sıklığının araştırılması. Turkish J Gastroenterol 1999; 1: 20-1.

24. Liebregts T, Adam B, Bredack C, Röth A, Heinzel S, Lester S, et.al. Immune activation in patients with irritable bowel syndrome. Gastroenterology 2007; 132: 913-20. [CrossRef]

25. Boorom KF, Smith H, Nimrii L, Viscogliosi E, Spanakos G, Parkar U, et al. Oh my aching gut: irritable bowel syndrome, Blastocystis, and asymptomatic infection. Parasit Vectors 2008; 21: 1: 40.

26. Stark D, Beebe N, Marriott D, Ellis J, Harkness J. Evaluation of three diagnostic methods, including real-time PCR, for detection of Dientamoeba fragilis in stool specimens. J Clin Microbiol 2006; 44: 232-5. [CrossRef]

27. Clark CG. Extensive genetic diversity in Blastocystis hominis. Mol Biochem Parasitol. 1997; 87: 79-83. [CrossRef]

28. Windsor JJ, Johnson EH. Dientamoeba fragilis: the unflagellated human flagellate. Br J Biomed Sci 1999; 56: 293-306.

29. Crotti D, Drannibale ML, Fonzo G, Lalle M, Cacciò SM, Pozio E. Dientamoeba fragilis is more prevalent than Giardia duodenalis in children and adults attending a day care centre in Central Italy. Parasite 2005; 12: 165-70. [CrossRef]

30. Walderich B, Bernauer S, Renner M, Knobloch J, Burchard GD Cytopathic effects of Blastocystis hominis on Chinese hamster ovary $(\mathrm{CHO})$ and adeno carcinoma HT29 cell cultures. Trop Med Int Health 1998; 3: 385-90. [CrossRef]

31. Girginkardeşler N, Kurt O, Kilimcioğlu AA, Ok UZ. Transmission of Dientamoeba fragilis: evaluation of the role of Enterobius vermicularis. Parasitol Int 2008; 57: 72-5. [CrossRef]

32. Ockert G, Schmidt T. On the epidemiology of Dientamoeba fragilis Jepps and Dobell 1918. 4th communication: evidence of Dientamoeba fragilis in Enterobius eggs using isoelectric point determination. J Hyg Epidemiol Microbiol Immunol 1976; 20: 76-81. 